\title{
MISTRAL MISTRAL
}

Journal of Latin American Women's

Intellectual \& Cultural History

3 poetas 3. Ensayos sobre la infancia en la obra de Juan Gelman, Alejandra Pizarnik y María Elena Walsh compilado por Fernando, Copello, Marina Letourner y Luce Valverde (reseña).

María José Punte, Universidad de Buenos Aires / Universidad Católica Argentina

To cite this review: María José Punte. 2021. Reseña de 3 poetas 3. Ensayos sobre la infancia en la obra de Juan Gelman, Alejandra Pizarnik y María Elena Walsh compilado por Fernando, Copello, Marina Letourner y Luce Valverde. Mistral: Journal of Latin American Women's Intellectual \& Cultural History 1 (2): 113-114, https://doi.org/10.21827/mistral.2.38035 
Fernando Copello, Marina Letourner y Luce Valverde (comps.), 3 poetas 3. Ensayos sobre la infancia en la obra de Juan Gelman, Alejandra Pizarnik y María Elena Walsh. Buenos Aires: Dedalus, 2020. 122 págs. ISBN 978-987-3744-64-8

La propuesta de este libro, que recoge seis ensayos y una conversación, es doble: hablar de la infancia y generar un diálogo entre tres poetas cuyas obras mantienen en cada caso sus características tan originales como propias. Dos autoras y un autor -Alejandra Pizarnik, María Elena Walsh y Juan Gelman-, que llevaron adelante proyectos poéticos diversos, viviendo en contextos no siempre coincidentes. La obra de estxs tres poetas permite una entrada hacia y desde el tópico de la infancia, armando figuras al modo del caleidoscopio. Los números, por su parte, atraviesan el libro de varias maneras que remiten tanto a lo lúdico como a lo artificioso de la niñez, en particular si tenemos en cuenta que la voz poética habla a la infancia desde experiencias que no pueden venir más que de la adultez. En la introducción, sus compiladores Fernando Copello, Marina Letourner y Luce Valverde enuncian que "Hablar de la infancia es una manera de decir el mundo, evocar la creación particular de cada ser y su entrada en el universo social. Hablar del niño es para cada poeta una manera privilegiada de hablar de sí mismo siendo al mismo tiempo el otro, el que permaneció en el pasado" (13). Si bien, en el caso de lxs tres poetas que estimularon la escritura y publicación de estos textos mantuvieron a través de sus obras relaciones muy especiales con el universo infantil, la elección de esta puerta de entrada supone por parte de los y las compiladores, así como de los y las articulistas, una toma de posición específica para volver a leerlos a partir de una determinada constelación de sentidos.

El título elegido es un guiño que remarca la aceptación del juego como forma de pensamiento. 3 poetas 3 debe su feliz inspiración a una dedicatoria hecha por María Elena Walsh, como se consigna en las palabras preliminares. Suma palabras y letras, al modo infante. El juego propuesto por Walsh, el de una estructura "capicúa", trae consigo el sabor de los usos cotidianos y populares del lenguaje, lo que es una marca registrada de toda su obra poética. El juego, por lo tanto, más que un tópico remite a los modos en los que estxs tres autores asumieron al lenguaje, exploraron sus posibilidades, y abrieron de esa manera las dimensiones de lo común y compartido. La infancia retorna en cada una de estas obras de manera diferente: como memoria, en tanto que perspectiva miniaturizada, como rebelión.

La entrada a la obra de Juan Gelman está a cargo de Geneviève Fabry, autora del libro Las formas del vacío. La escritura del duelo en la poesía de Juan Gelman (2008). Su texto opta por analizar la relación de la infancia en tanto que lenguaje a partir de tres ejes: uno que rastrea la noción de "niño esencial" en ejemplos tomados de Violín y otras cuestiones (1956) y en el poema-oratorio La junta luz (1985); un segundo apartado en el que piensa la figura del niño/hijo a través de los poemarios Los poemas de Sidney West (1969) y Notas, Carta abierta (1980); en tercer lugar, aborda la persistencia de la niñez en relación con la sustancia de lo poético en los poemarios Eso (1986) y El emperrado corazón amora (2011). El hilo de la infancia que recorre la autora le permite analizar un trabajo persistente e incisivo sobre el lenguaje a través del cual se devela aquello que subyace a la experiencia cotidiana, que cuestiona a un mundo tramado desde violencias (políticas, como las sufridas por Gelman y su familia, pero también otras que son propias del espacio urbano). 
Tres textos tres son dedicados a la poeta Alejandra Pizarnik: los ensayos de Ivonne Bordelois y de Edgardo Dobry, y la entrevista-conversación que cierra el volumen y que Elena Savransky y Fernando Copello realizan en agosto de 2014 a Betty Sapollnik, amiga de la infancia de la poeta. Bordelois reflexiona sobre la idea de inocencia para pensar a Pizarnik desde su evidente intensidad, lo que la autora define como una "incandescencia desconocida" (33) que Alejandra imprime en la lengua poética en español. Retorna a esta idea de que la inocencia en Pizarnik es una forma de "candor nocturno", en una exploración poética que no evita confrontar con el mal, sino que busca exorcizarlo a través de la poesía. Pensar que en Alejandra conviven la infancia y la adolescencia con la edad adulta, significa para Bordelois que en ella están la capacidad de asombro y el juego, la inquietud y la angustia, la sabiduría y la lucidez. Edgardo Dobry, por su parte, se concentra en la cuestión de la glosolalia en los textos "malditos" de la autora, y la vincula con la condición de infans, del momento preverbal del lenguaje (tema desarrollado por Giorgio Agamben). Tres aspectos para volver a hacer volver a la niña que hay en Pizarnik: desde la semántica, desde la semiótica, desde la evocación amorosa.

Por último, tres textos tres para María Elena Walsh. Fernando Copello va siguiendo los vínculos de la "juglaresa" con la escuela, para pensar cómo aparecen entrelazados aprendizaje y juego. La escuela como tópico es evidente en el querido poema "La vaca estudiosa" (Tutú Marambá, 1960), pero también está en el entramado que va siguiendo el autor desde la novela Novios de antaño (1930.1940), en conferencias de la autora, en su libro de lectura escolar Aire libre (1967), hasta llegar al texto que la posicionó sin dudas como autora política: País Jardín de Infantes (1979). La relación de María Elena Walsh con la escuela se devela como compleja y contradictoria, pero claramente vinculada con los modos en los que ella logra condensar tradiciones provenientes de las culturas anglosajona y del folclore latinoamericano en un estilo propio e inconfundible. El segundo texto es de Gabriele Hassler y se concentra en otro aspecto: la maternidad leída en clave feminista. Hace un recorrido a través de varios poemarios de la autora menos trabajados, como Otoño imperdonable (1947), Baladas con Ángel (1952), Hecho a mano (1965). Es posible rastrear una metáfora de maternidad que le sirve a Walsh para construir un sujeto poético desde una genealogía de mujeres creadoras. Por su parte, Maud Gaultier piensa infancia y poesía para ver los modos en los que fue cambiando la concepción de lo infante en los años sesenta. Walsh comprendió muy bien estos cambios y los expresó en un arte que puso a niños y adultos en plano de igualdad.

Este libro, que surge en el marco de proyectos de investigación radicados en el laboratorio 3LAM de la Université de Le Mans, y que ya había dado como resultado el volumen Infancias/Enfances (2017), supone un bienvenido aporte a los estudios sobre estxs tres autores. Pero, a su vez, suma a una construcción que viene marchando con paso lento pero seguro en los estudios de infancia y literatura. Lo hace, una vez más, reforzando los lazos transatlánticos entre Francia y Argentina.

María José Punte

Universidad de Buenos Aires

Universidad Católica Argentina 